NASA/CR—2005-213417

\title{
Wind-US Unstructured Flow Solutions for a Transonic Diffuser
}

Stanley R. Mohler, Jr.

QSS Group, Inc., Cleveland, Ohio 
Since its founding, NASA has been dedicated to the advancement of aeronautics and space science. The NASA Scientific and Technical Information (STI) Program Office plays a key part in helping NASA maintain this important role.

The NASA STI Program Office is operated by Langley Research Center, the Lead Center for NASA's scientific and technical information. The NASA STI Program Office provides access to the NASA STI Database, the largest collection of aeronautical and space science STI in the world. The Program Office is also NASA's institutional mechanism for disseminating the results of its research and development activities. These results are published by NASA in the NASA STI Report Series, which includes the following report types:

- $\quad$ TECHNICAL PUBLICATION. Reports of completed research or a major significant phase of research that present the results of NASA programs and include extensive data or theoretical analysis. Includes compilations of significant scientific and technical data and information deemed to be of continuing reference value. NASA's counterpart of peerreviewed formal professional papers but has less stringent limitations on manuscript length and extent of graphic presentations.

- TECHNICAL MEMORANDUM. Scientific and technical findings that are preliminary or of specialized interest, e.g., quick release reports, working papers, and bibliographies that contain minimal annotation. Does not contain extensive analysis.

- CONTRACTOR REPORT. Scientific and technical findings by NASA-sponsored contractors and grantees.
- CONFERENCE PUBLICATION. Collected papers from scientific and technical conferences, symposia, seminars, or other meetings sponsored or cosponsored by NASA.

- SPECIAL PUBLICATION. Scientific, technical, or historical information from NASA programs, projects, and missions, often concerned with subjects having substantial public interest.

- TECHNICAL TRANSLATION. Englishlanguage translations of foreign scientific and technical material pertinent to NASA's mission.

Specialized services that complement the STI Program Office's diverse offerings include creating custom thesauri, building customized databases, organizing and publishing research results ... even providing videos.

For more information about the NASA STI Program Office, see the following:

- Access the NASA STI Program Home Page at http://www.sti.nasa.gov

- E-mail your question via the Internet to help@sti.nasa.gov

- Fax your question to the NASA Access Help Desk at 301-621-0134

- Telephone the NASA Access Help Desk at 301-621-0390

- Write to:

NASA Access Help Desk

NASA Center for AeroSpace Information 7121 Standard Drive

Hanover, MD 21076 
NASA/CR-2005-213417

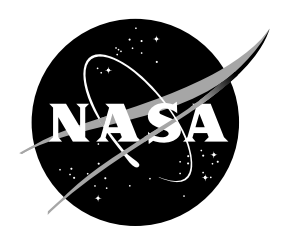

\section{Wind-US Unstructured Flow Solutions for a Transonic Diffuser}

Stanley R. Mohler, Jr.

QSS Group, Inc., Cleveland, Ohio

Prepared for the

43rd Aerospace Sciences Meeting and Exhibit

sponsored by the American Institute of Aeronautics and Astronautics

Reno, Nevada, January 10-13, 2005

Prepared under Contract NAS3-00145

National Aeronautics and

Space Administration

Glenn Research Center 


\section{Acknowledgments}

The author wishes to thank S.V. Ramakrishnan for advice on the unstructured solver, and Chris Nelson for advice on the structured solver. This work was supported by the NASA Glenn Research Center under contract NAS3-00145 with QSS Group, Inc.

Trade names or manufacturers' names are used in this report for identification only. This usage does not constitute an official endorsement, either expressed or implied, by the National Aeronautics and Space Administration.

This work was sponsored by the Low Emissions Alternative

Power Project of the Vehicle Systems Program at the NASA Glenn Research Center.

Available from

NASA Center for Aerospace Information 7121 Standard Drive

Hanover, MD 21076
National Technical Information Service 5285 Port Royal Road Springfield, VA 22100 


\title{
Wind-US Unstructured Flow Solutions for a Transonic Diffuser
}

\author{
Stanley R. Mohler, Jr. \\ QSS Group, Inc. \\ Cleveland, Ohio 44135
}

\begin{abstract}
The Wind-US Computational Fluid Dynamics flow solver computed flow solutions for a transonic diffusing duct. The calculations used an unstructured (hexahedral) grid. The Spalart-Allmaras turbulence model was used. Static pressures along the upper and lower wall agreed well with experiment, as did velocity profiles. The effect of the smoothing input parameters on convergence and solution accuracy was investigated. The meaning and proper use of these parameters are discussed for the benefit of Wind-US users. Finally, the unstructured solver is compared to the structured solver in terms of run times and solution accuracy.
\end{abstract}

\section{Introduction}

Recently, the NPARC Alliance added an unstructured grid capability to its WIND Computational Fluid Dynamics flow solver (refs. 1 to 5). With this change, the flow solver is now called Wind-US rather than WIND. Wind-US computes viscous, compressible flows using structured, unstructured, and hybrid grids. Unstructured grids may consist of any element type including hexahedral, pentahedral (prismatic and pyramidal), and tetrahedral.

The NPARC Alliance maintains a public Web-based database of verification and validation (V\&V) cases that were run using Wind-US. The Web address is http://www.grc.nasa.gov/WWW/wind/valid/. In addition to verifying and validating the flow solver, these cases serve as tutorials that users can run in order to learn the NPARC Alliance software.

The V\&V Web site contains numerous cases that used structured grids but almost none using unstructured grids. The current study provides an unstructured version of a currently existing structured case, specifically the transonic diffuser case. The structured grid version of the study is described online at http://www.grc.nasa.gov/WWW/wind/valid/transdif/transdif.html. Experimental studies on this diffuser are described in references 6 to 9. The flow covered both subsonic and supersonic flow regimes, contained a normal shock that induced boundary layer separation, and had an adverse pressure gradient in the subsonic region behind the shock.

The purposes of this study are to (1) replicate the NPARC transonic diffuser structured grid validation case using the new unstructured solver, (2) examine the effect of the smoothing inputs on the computed solution, and (3) compare the structured and unstructured solvers in regards to computer resource use and agreement with experiment.

\section{Experimental Approach}

\section{Diffuser Model}

The diffuser was a converging-diverging channel designed to produce an approximately 2-D flow field. The duct was rectangular in cross-section, with bottom and side-wall slots at several axial stations to pull off the boundary layers. The throat height was about 1.73 inches $(44 \mathrm{~mm})$. The ratio of exit area to throat area was 1.5. A drawing of the diffuser is shown in figure 1 with dimensions in millimeters. At the upstream end, a plenum supplied dry, filtered air through a screen, providing uniform, low-turbulence flow. At the exit, the model is vented directly to the atmosphere, providing a constant-pressure downstream boundary condition. 


\section{Experimental Flow Features}

The flow features seen in this diffuser are depicted in figure 2. Though this figure shows a different diffuser, the experimentalists used this figure in reference 6 to describe the flow field of the current diffuser. The flow accelerates through sonic at the throat. Shortly downstream of the throat, a normal shock with a lambda pattern appears. For flow conditions with higher shock strengths, the shock induced separation at the upper wall, and a degree of unsteadiness persisted. Under all conditions, the flow reattached upstream of the exit station shown in figure 1 . Though the diffuser was designed to produce an approximately 2-D flow, there was some vortical structure with spanwise movement of air. The dark gray regions in figure 2 show the growth and merging of the boundary layers.

\section{Instrumentation}

In the course of several experimental investigations on this diffuser, various instrumentation arrangements measured instantaneous and time-averaged pressures, flow velocities, surface streamlines, and shock positions. Images of the flow field were created using shadowgraph, Schlieren, and LDV systems. Of interest to the current study, static pressure ports were embedded in the top and bottom walls along the length of the duct at mid-span in order to measure the time-mean static pressures. A dual-pressure probe extended up into the flow from the bottom wall to measure total and static pressure profiles at various axial stations, from which velocity profiles were derived.

\section{Flow Conditions}

The flow condition was characterized by the Mach number going into the shock at the edge of the upper wall boundary layer. This Mach number ranged from a low of about 1.18 to a high of about 1.35. The Reynolds number reached a high of about $5.3 \times 10^{5}$ per inch. The flow condition was set by adjusting the pressure in the upstream plenum chamber. Shock induced flow separation occurred on the upper wall for shock Mach numbers above about 1.27. The current study used one condition, for which the shock Mach number was about 1.33 . On the V\&V Web site and in this study, this condition is named the "Strong Shock Case."

The top wall boundary layer was tripped at the upstream end, as seen in figure 1, to produce a fully turbulent flow. The side and bottom walls were expected to remain laminar up to the shock.

\section{Computational Approach}

\section{Grid Generation}

In order to allow direct comparison of the unstructured solutions with the previously calculated structured ones, the structured grids were used for the unstructured calculations. The structured grid is $81 \mathrm{x} 51$ in size and is shown in figure 3. Note that " $\mathrm{H}^{*}$ " is the throat height. This grid was used by 


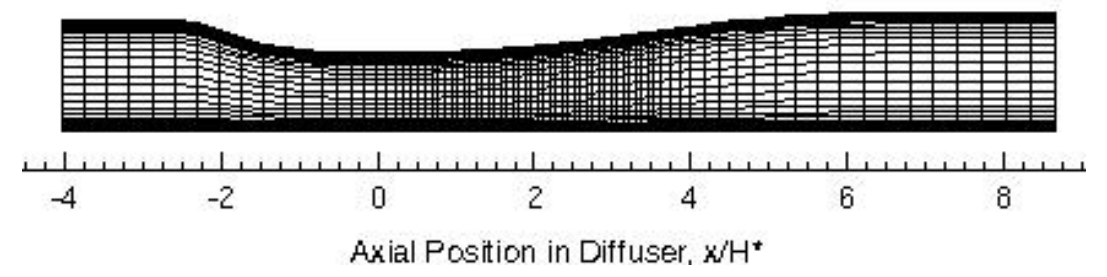

Figure 3.-Hexahedral grid.

Georgiadis et al (ref. 10). who found the first grid point off the walls to lie within the laminar sublayer. The grid can be obtained from the V\&V web site.

Since the cell-centered unstructured solver requires a 3-D grid, the 81 x 51 grid was extended 1 grid cell of 2 inch distance in the spanwise direction, producing an $81 \times 51 \times 2$ structured grid. This grid was converted to unstructured hexahedral representation for the unstructured solver, i.e., the $\mathrm{I} / \mathrm{J} / \mathrm{K}$ indices were eliminated and each of the 4,000 cells was given a single unique index number. The MADCAP preprocessor, which comes with Wind-US, performed this conversion automatically.

The use of general unstructured cell types with Wind-US, i.e., tetrahedra, prisms, and pyramids, was described by the author in ref. 5 .

\section{Boundary Conditions}

At the inflow plane, an Arbitrary Inflow boundary condition was imposed with a specified total pressure of 19.5 psi and total temperature of $500{ }^{\circ} \mathrm{R}$. The flow condition was set by setting the static pressure imposed at the outflow boundary to $14.1 \mathrm{psi}$. These inflow and outflow boundary conditions are identical to those used for the Strong Shock structured solver case on the V\&V Web site. Viscous walls were imposed at the top and bottom walls. The structured grid studies for this diffuser on the V\&V web site were 2-D, and so did not model the side walls. The equivalent situation for the current study would impose an inviscid planar wall BC. The Singular Axis BC was chosen to avoid the needless computation of pressure fluxes normal to the boundary that would be computed by an inviscid wall BC but which are unnecessary for this case since the side walls are flat and parallel.

\section{Initial Conditions}

The flow field was initialized as uniform Mach 0.9 flow in the $\mathrm{x}$ direction. The total pressure was $19.5 \mathrm{psi}$, and the total temperature was $500^{\circ} \mathrm{R}$.

\section{Computational Strategy}

The Wind-US 1.0 unstructured flow solver uses a cell-centered finite volume method where the integral form of the RANS equations are discretized using a $2^{\text {nd }}$ order upwind scheme in space and $1^{\text {st }}$ order backward differencing in time. References 3 and 4 thoroughly describe the algorithm. The upwind fluxes are computed either by Roe's scheme, or a modified Rusanov's scheme, or the HLLE scheme. The choice is specified by the user after the "RHS" input keyword in the ".dat" input file. According to reference 2, the preferred upwinding scheme for the unstructured solver in Wind-US is the modified Rusanov scheme. This preference is due to the Rusanov scheme's greater stability over Roe above about Mach 2 while giving comparable solutions for low levels of dissipation, according to S.V. Ramakrishnan of HyPerComp, Inc. (The Roe scheme is recommended for the structured solver.) The HLLE scheme is a combination of Roe and Rusanov that may prove best for real gases and finite rate chemistry. The unstructured solver calculations in the current study used the modified Rusanov scheme, with one unstructured Roe and two structured calculations made for comparison.

Local time-stepping was used to converge on a steady-state solution. The Spalart-Allmaras turbulence model was used. Some calculations were run until the L2 residuals of both the Navier-Stokes and SpalartAllmaras solvers converged while others were run until the pressure and viscous loads converged. 


\section{Input Parameters}

Smoothing parameters: SECOND, FOURTH, SMLIMT and DEBUG 19.-When running the unstructured solver in Wind-US, there are some smoothing parameters the user should be familiar with. Their purpose is to increase the stability of the solver. They are input after the SMOOTHING keyword in the ".dat" input file, and are named SECOND, FOURTH, and SMLIMT. (Note that these three keywords may eventually be moved to the "TVD" keyword instead of "SMOOTHING" to be consistent with the structured solver, according to Chris Nelson of ITAC, Inc.) The SECOND and FOURTH parameters retain their names from the second and fourth order dissipation available to the structured solver with the central differenced RHS. But for the unstructured solver, the three parameters mean something entirely different.

For the modified Rusanov unstructured scheme, SECOND means "upwind flux dissipation." It is the parameter delta (ref. 3) and dissip (ref. 4) used in the calculation of the inviscid upwind fluxes. A value of 1.0 imposes the original Rusanov scheme, while values less than 1.0 impose S.V. Ramakrishnan's modified Rusanov scheme which has less flux dissipation. Maximum stability occurs for a value of about 0.5 , and is good for starting a calculation. Reduction to the 0.1 to 0.25 range increases accuracy at the expense of stability. This dissipation is applied throughout the flow field uniformly. SECOND is unused for the Roe unstructured scheme.

For both Rusanov and Roe unstructured schemes, FOURTH means "Jacobian dissipation." This is the relaxation parameter beta used to compute the inviscid Jacobians (ref. 3). FOURTH should always be set to the default of 1.5.

For the unstructured schemes, SMLIMT means "TVD slope limiter." It's the parameter cmp in the minmod operator as described in references 3 and 4. SMLIMT limits the gradients of the Q variables at cell centers so that no new local maximum or minimum values of the $Q$ variables appear upon extrapolation to face centers where the upwind fluxes are computed. This slope limiting is necessary for stability as well as to meet the TVD condition (ref. 11). A low input value is the most stable while higher values are more accurate. For the Rusanov unstructured solver, the Wind-US manual (ref. 2) recommends starting your calculation at 1.0 and then trying to raise SMLIMT up somewhere near 4.0 later. For the Roe unstructured solver, the recommended starting value is 1.2, and the target value is 1.5.

Each of the unstructured schemes can be optionally modified by turning on the "constant enthalpy scheme" as described in reference 4 (activated by adding "DEBUG 19 1" to the ".dat" input file). The constant enthalpy scheme adds dissipation to the calculations, and is a necessary capability to compute accurate hypersonic flow fields. The DEBUG 19 option was not used in the current study.

The output file named "nbad" reports, for each zone, how many grid cells were reduced from spatially $2^{\text {nd }}$ order calculations to $1^{\text {st }}$ order as the solver iterated. This number, labeled $n B a d$, should decrease over time. If the final value of $n \mathrm{Bad}$ is more than a small number, and the CFL number is not too high, then SECOND should be raised, or SMLIMT should be reduced, or both (as recommended by S.V. Ramakrishnan). The calculations in this study finished with values of $\mathrm{nBad}$ close to 0 .

CFL number.- Since the unstructured solver in Wind-US is point-implicit, it has been suggested that higher CFL numbers can be used than for the line-implicit structured solver. For the unstructured solver, the Wind-US User's Manual (ref. 2) suggests a CFL number of 10 at the start of a calculation, and as high as 50 for later runs. A value of 10 was used in the current study. These remarks apply when local time stepping is used (steady-state mode).

GRID LIMITER angle.-In order to improve stability, this input parameter makes the scheme locally $1^{\text {st }}$ order in space where ever the grid bends more than "angle" degrees. A value of $150^{\circ}$ was used in the current study. To understand this parameter, imagine two connected line segments, the first starting at a cell center and ending on the center of one of that cell's faces, and another line segment starting right there and ending at the center of the neighboring cell. In general, passage along these two line segments, from cell center to cell center via the common face center, will entail some angular bend. For highly skewed cells, that bend angle can become large, almost $180^{\circ}$, and the $2^{\text {nd }}$ order scheme can become unstable. Reduction to $1^{\text {st }}$ order increases stability. 
Diagonal versus Block Solver.-The IMPLICIT UGAUSS keywords allow the user to specify whether the Gauss-Seidel implicit operator uses a full block matrix or diagonal matrix. Usually diagonal matrix is used, and was used in this study. According to S.V. Ramakrishnan, full block solution is about 10 percent slower, but is more stable. Therefore, for unstable problems, full block may be an alternative to excessive smoothing.

\section{Post-processing}

Convergence histories, static pressures and velocity profiles were plotted using the CFPOST utility that comes with Wind-US. The FieldView commercial software package plotted Mach contours.

\section{Results}

Figure 4 shows a flow solution in the form of Mach contours computed by the Wind-US alpha unstructured Rusanov solver. The Mach number approaches 1.4 just upstream of the shock. Immediately downstream of the shock, a shock-induced separation bubble resides against the upper wall.

The choice of smoothing inputs can drastically affect a flow calculation. To illustrate the extremes, two calculations were run using the Rusanov unstructured solver. One calculation used minimal smoothing (SECOND=0.1, SMLIMT=4.0), and the other imposed the maximum used in this study $(\mathrm{SECOND}=0.5, \mathrm{SMLIMT}=1.0)$. For both calculations, the convergence histories of the L2 norm of the Navier-Stokes equations are plotted in figure 5. Figure 6 similarly plots the convergence of the SpalartAllmaras turbulence model. These two figures clearly show that more smoothing leads to a greater reduction in the residuals. Note that the lingering noise and jaggedness in the residuals are likely due to the unsteadiness in the flow seen in the experiments involving a $200 \mathrm{~Hz}$ oscillation in shock position. This jaggedness was absent from a Weak Shock calculation (not shown).

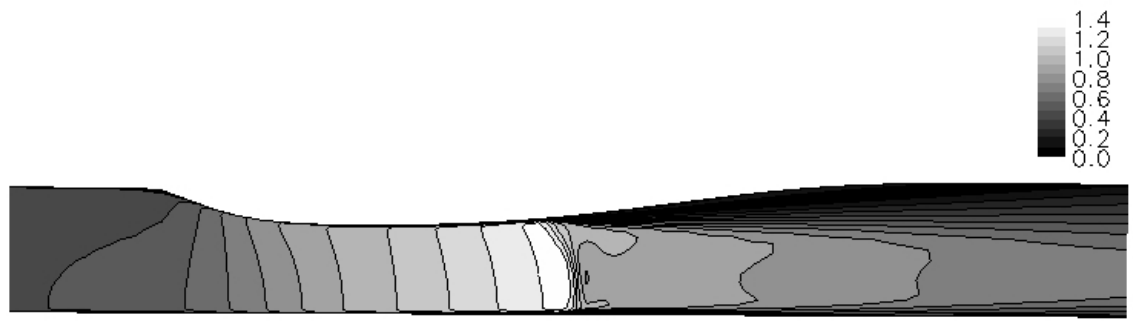

Figure 4.--Mach contours computed by Wind-US.

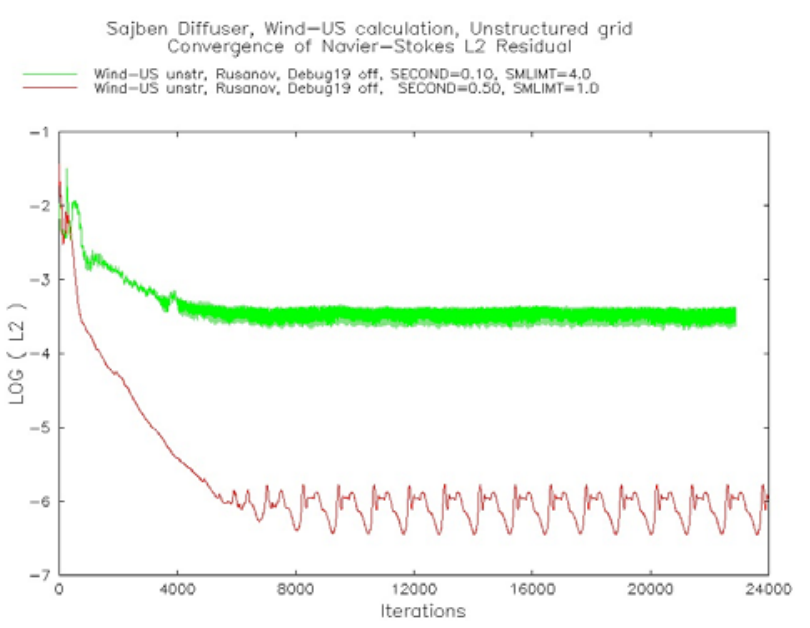

Figure 5.-Convergence of N-S equations for the

Rusanov unstructured solver-minimum versus maximum smoothing.

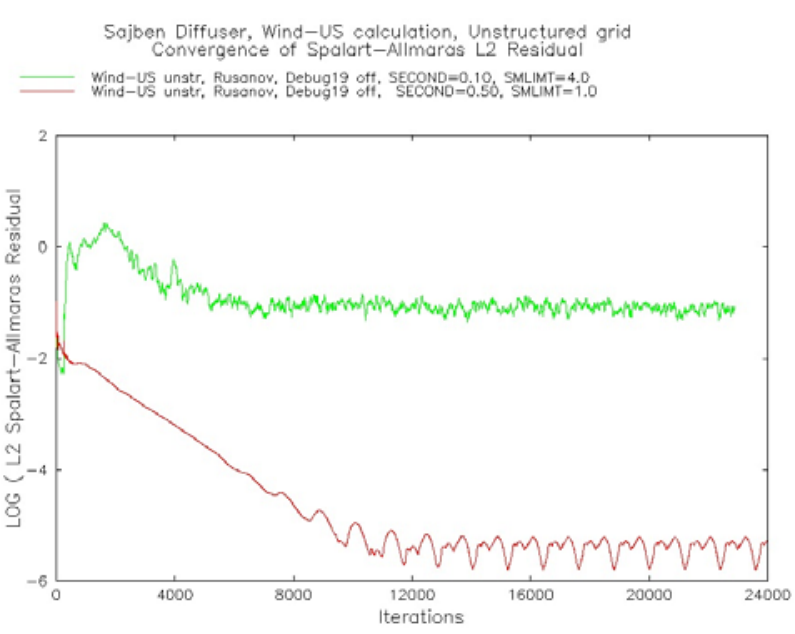

Figure 6.-Convergence of S-A turbulence model for the Rusanov unstructured solver-minimum versus maximum smoothing. 
On the other hand, less smoothing clearly produces a more accurate solution, as shown in figures 7 to 12. Figures 7 and 8 show static pressures along the lower and upper walls of the diffuser. The excessive smoothing in one calculation causes strong disagreement with experiment while minimum smoothing agrees well. In the two figures, one can see the shock location where the static pressure makes a sudden rise from the minimum value. The better solution agrees in both value of static pressure and shock location.

Figures 9 to 12 show velocity profiles at four stations whose locations are given as $\mathrm{x} / \mathrm{H}^{*}$ used in figure 3. For the most part, the minimal smoothing solution agrees well with experiment, including speeds of the reverse flow. There is less agreement at the two downstream stations (figs. 11 and 12), possibly due to the 3-D effects seen in the experiment but unreproducible in the current 2-D calculations. However the high-smoothing profiles agree poorly, and fail to separate.

The effect of the smoothing parameters on solution accuracy will be investigated next. These inputs include the parameters SECOND and SMLIMT.

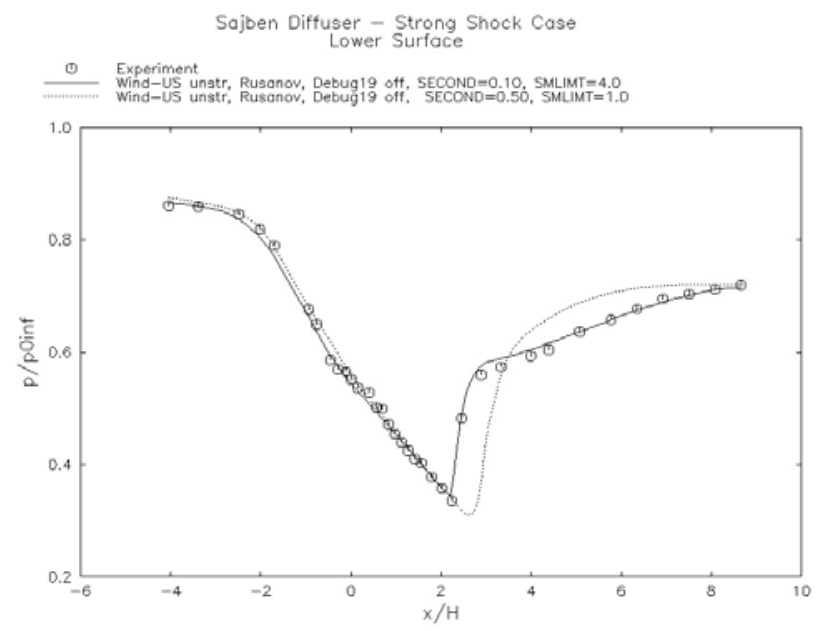

Figure 7.- - Lower wall static pressuresunstructured solver, min versus max smoothing.

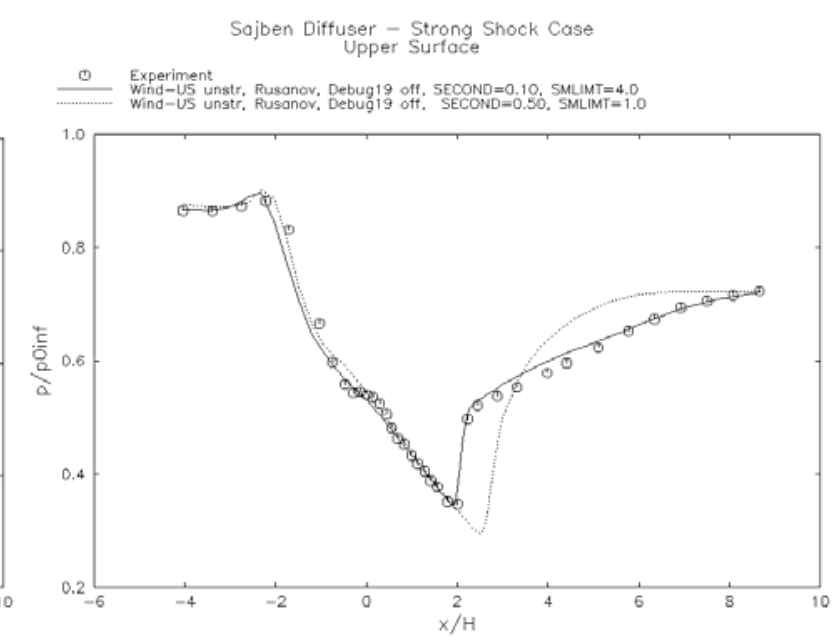

Figure 8.-Upper wall static pressuresunstructured solver, min versus max smoothing.

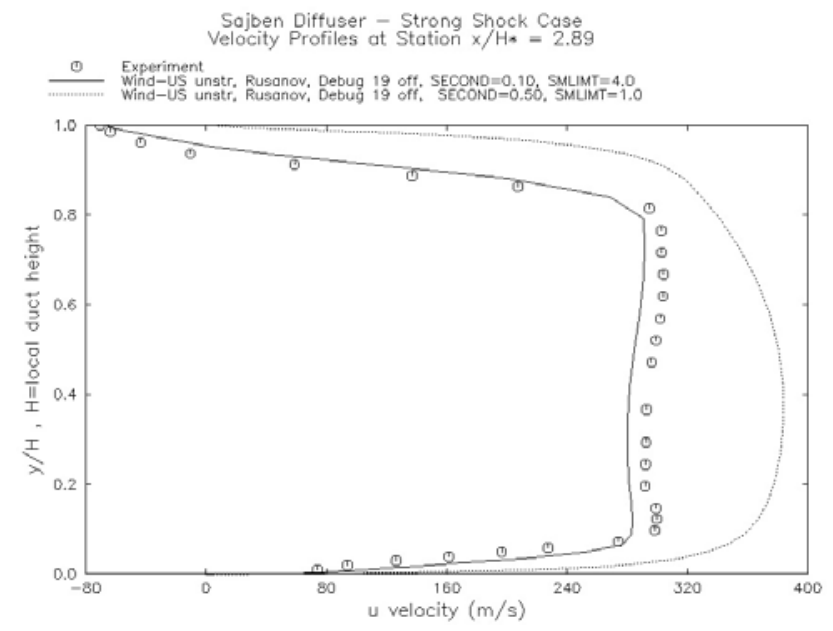

Figure 9.-Velocity profiles at $\mathrm{x} / \mathrm{H}^{*}=2.89$.

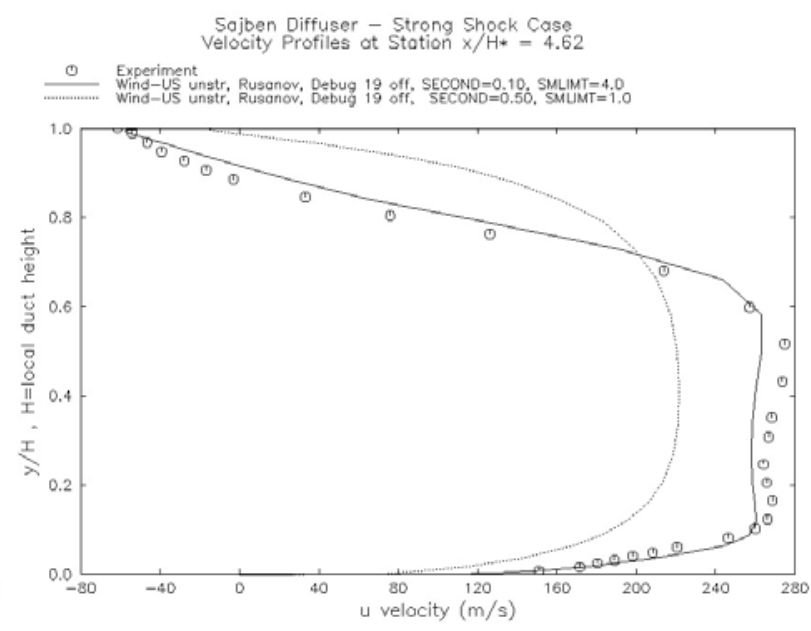

Figure 10.- Velocity profiles at $\mathrm{x} / \mathrm{H}^{*}=4.62$. 


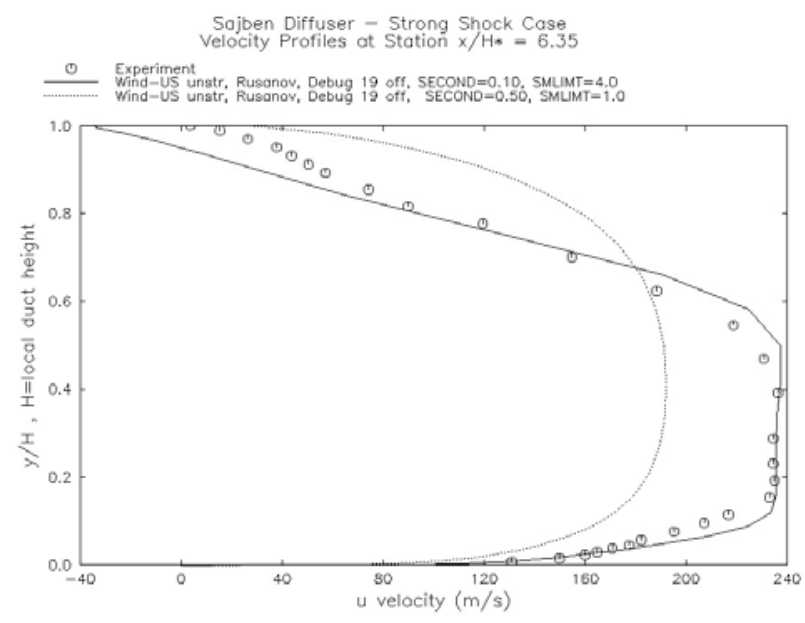

Figure 11.-Velocity profiles at $\mathrm{x} / \mathrm{H}^{*}=6.35$.

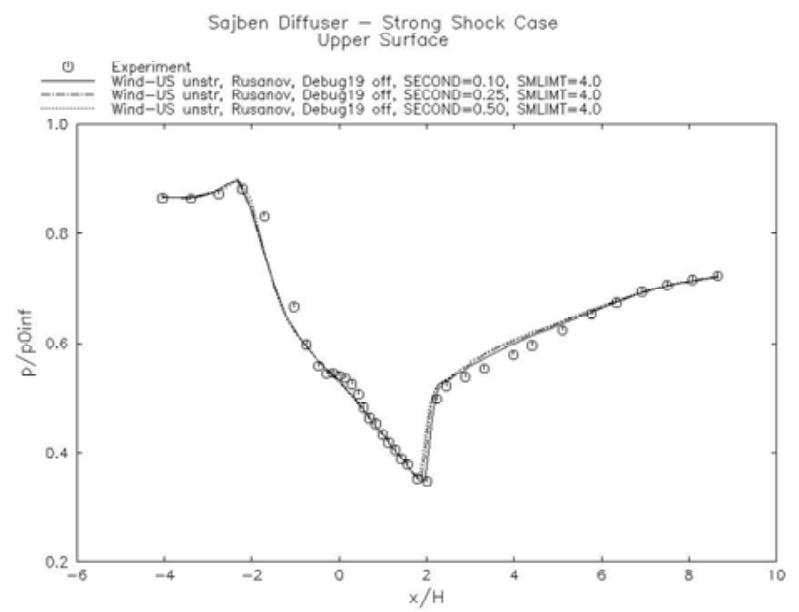

Figure 13a.--Upper wall static pressures for various values of SECOND.

\section{Effect of Varying the Upwind Flux Dissipation ("SECOND")}

Figures 13a and 13b show surface pressures on the upper wall computed using various values of upwind flux dissipation. The slope limiter was set to 4.0 to minimize its influence. One can see that greater dissipation corresponds to slightly less agreement between computed pressures and experiment. Figure 13b shows that smaller dissipation values lead to more accurate calculation of shock location.

Figure 14 shows the corresponding velocity profiles at station $\mathrm{x} / \mathrm{H}^{*}=4.62$. Minimal dissipation corresponds to marginally improved agreement with experiment.

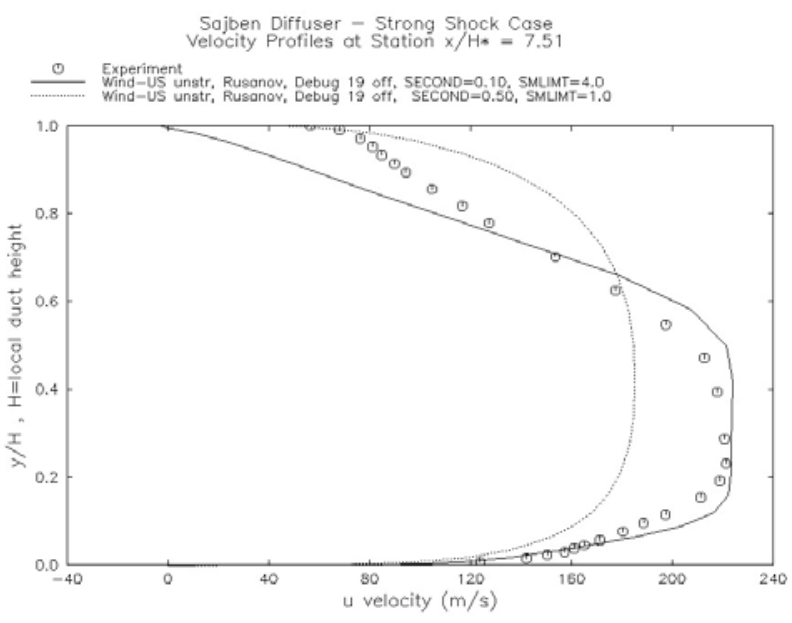

Figure 12.-Velocity profiles at $\mathrm{x} / \mathrm{H}^{*}=7.51$.

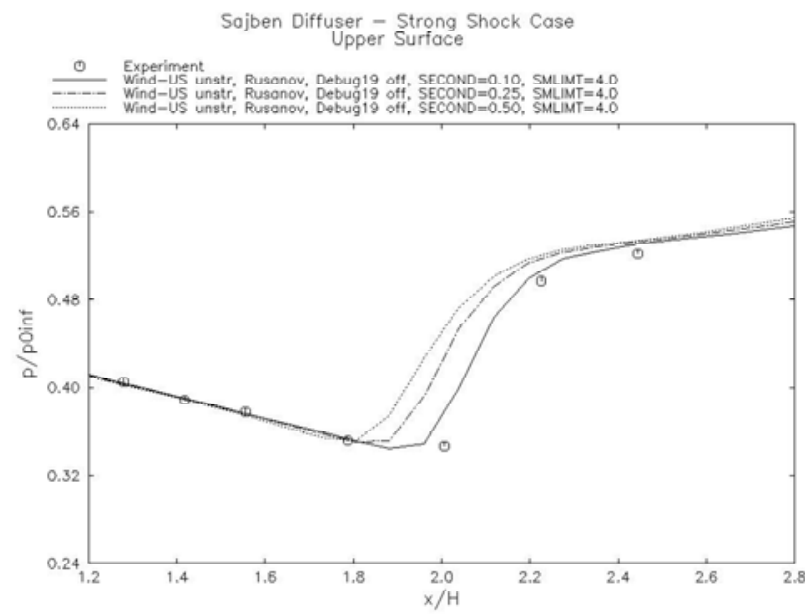

Figure $13 b .-$ Close-up of figure $13 a$.

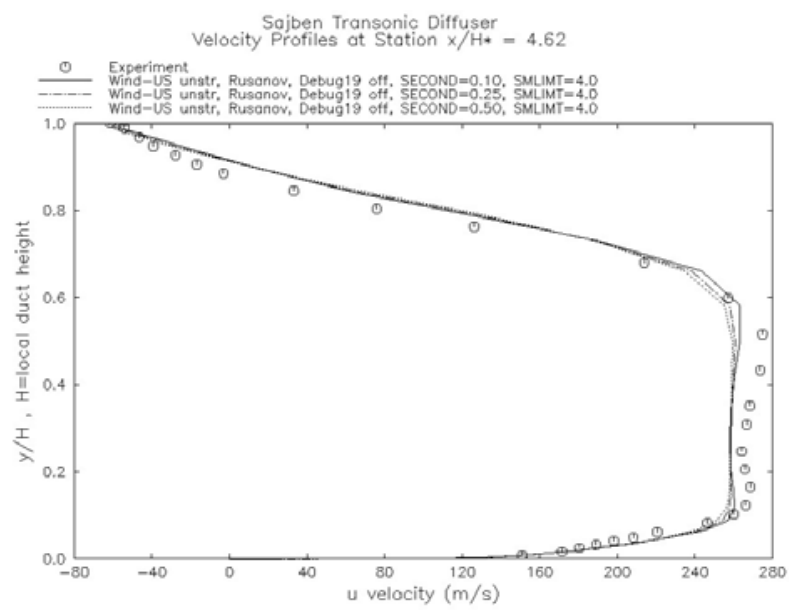

Figure 14.--Velocity profile for various values of SECOND. 


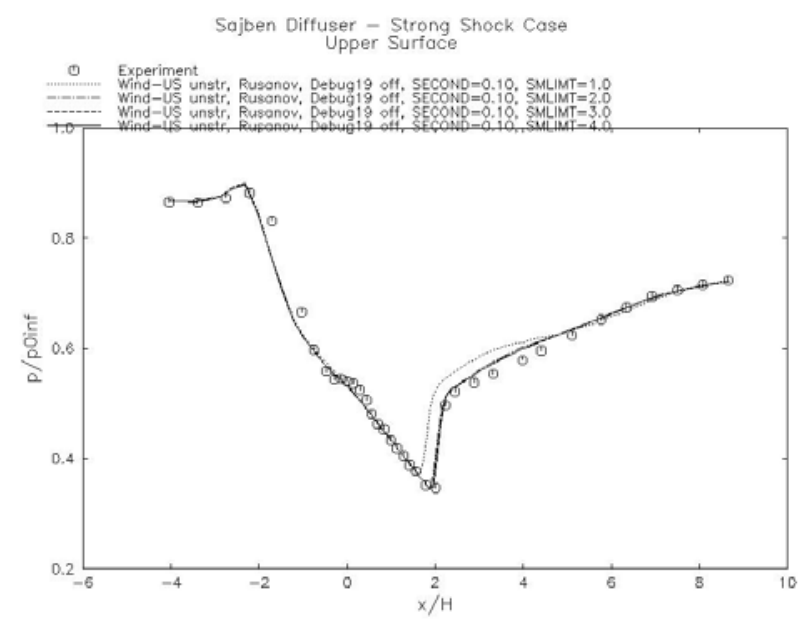

Figure 15a.-Upper wall static pressures for various values of SMLIMT.

\section{Effect of Varying Slope Limiter ("SMLIMT")}

Figures $15 \mathrm{a}$ and $15 \mathrm{~b}$ show static pressures on the upper wall for four values of SMLIMT. The flux limiter (variable SECOND) was set to 0.1, the lowest recommended value, to minimize its influence. For SMLIMT=1.0, agreement is noticeably poor. Setting SMLIMT to 2.0 or more leads to more accurate calculation of pressures and shock location.

Figure 16 shows the corresponding velocity profiles at station $\mathrm{x} / \mathrm{H}^{*}=4.62$. All 4 profiles appear almost identical. However, near the upper wall, SMLIMT $=1.0$ is noticeably worse than SMLIMT $=2.0$ and above.

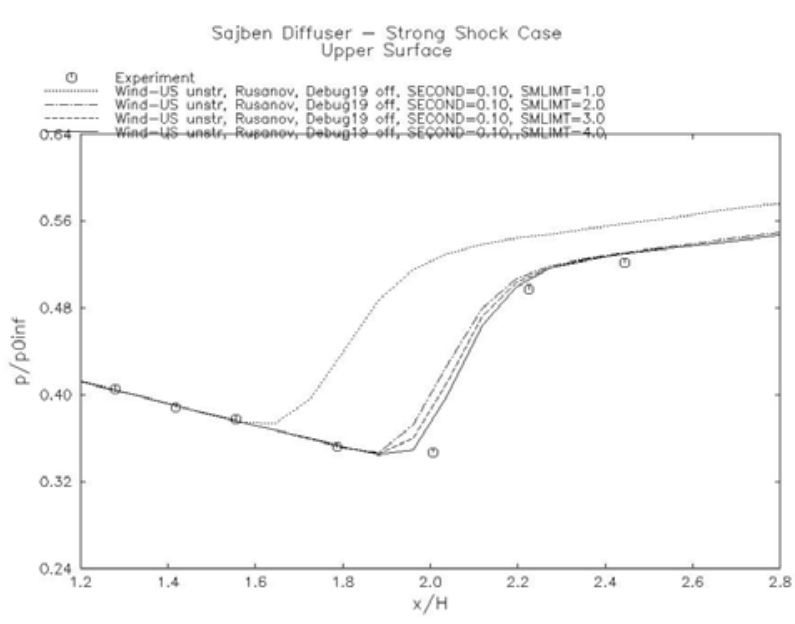

Figure 15b.-Close-up of figure 15a.

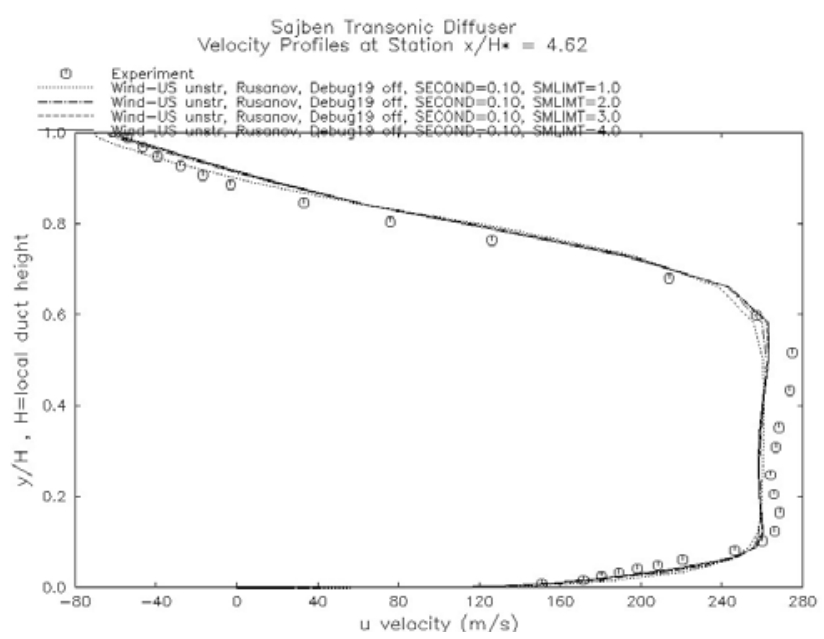

Figure 16.- Velocity profiles for various values of SMLIMT.

\section{Effect of Varying Upwind Flux Dissipation and Slope Limiter Simultaneously}

In each of the two previous sections, one smoothing parameter was varied while keeping the influence of the other minimized. In this section, both parameters are varied together.

Table 1 below shows the space of smoothing parameters covered. The previous two sections covered the parameter pairs labeled "A" and "B". This section will cover the pairs labeled "C" (shaded gray for emphasis).

\begin{tabular}{|c|c|c|c|c|}
\hline \multirow{3}{*}{\multicolumn{2}{|c|}{ (Min. smoothing at upper left) }} & able 1 & & \\
\hline & & \multicolumn{3}{|c|}{ SECOND } \\
\hline & & 0.1 & 0.25 & 0.5 \\
\hline \multirow{4}{*}{ SMLIMT } & 4 & $\mathrm{ABC}$ & $\mathrm{A}$ & A \\
\hline & 3 & $\mathrm{~B}$ & $\mathrm{C}$ & \\
\hline & 2 & $\mathrm{~B}$ & $\mathrm{C}$ & \\
\hline & 1 & B & & C \\
\hline
\end{tabular}

Figures $17 \mathrm{a}$ and $17 \mathrm{~b}$ show upper wall static pressures computed by the unstructured Wind-US Rusanov solver for the 4 parameter pairs labeled "C" in table 1 . The curve corresponding to maximal smoothing (lower-right cell in table 1: SMLIMT=1.0, SECOND=0.5) shows distinct disagreement with experiment, significantly worse than what was seen in the previous two sections where the influence of 


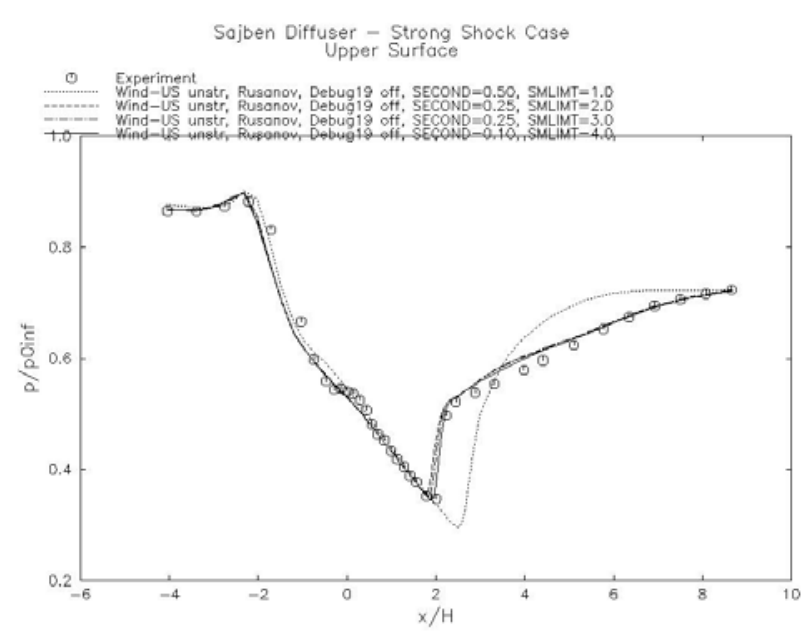

Figure 17a.-Upper wall static pressures for various combinations of SECOND and SMLIMT.

one or the other smoothing parameter was minimized. In other words, the poor solution produced by setting SMLIMT=1.0 is made much worse if SECOND is set larger than 0.25. Moving up and to the left in table 1, to SMLIMT=2.0 and $\mathrm{SECOND}=0.25$, brings the solution much closer to experiment. Further reduction of smoothing (moving towards the upper left in table 1) brings the computed pressures (and shock location) steadily but marginally closer to the experimental values (fig. 17b).

Figure 18 shows a similar trend of improvement in the velocity profile at station $\mathrm{x} / \mathrm{H}^{*}=4.62$. Most of the improvement in accuracy is accomplished by setting SECOND to 0.25 or below and SMLIMT to 2.0 or above.

\section{Use of CONVERGE LOADS Convergence Strategy}

The Wind-US unstructured solver allows automatic relaxation of the smoothing as the computed loads converge, with automatic halt of the calculation once the smoothing parameters reach the default final values and all the pressure and viscous loads are varying less than some percentage of their latest computed values. The loads tend to converge sooner than the L2 residuals. An example of this can be seen by looking at figure 19, which shows the convergence of the viscous drag for the minimum dissipation run, and comparing it to the upper curves in figures 5 and 6 . The viscous drag has converged in about 2000 iterations (400 cycles) while the

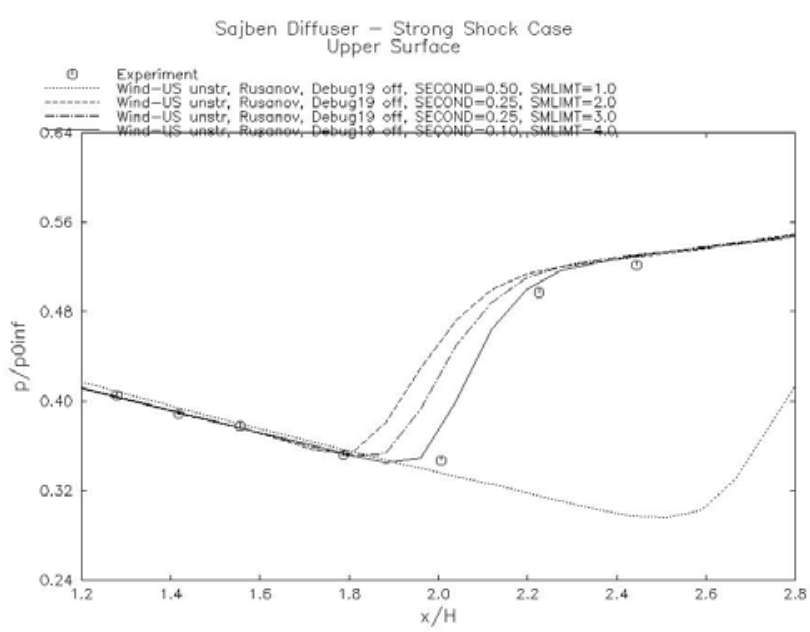

Figure 17b.-Close-up of figure 17a.

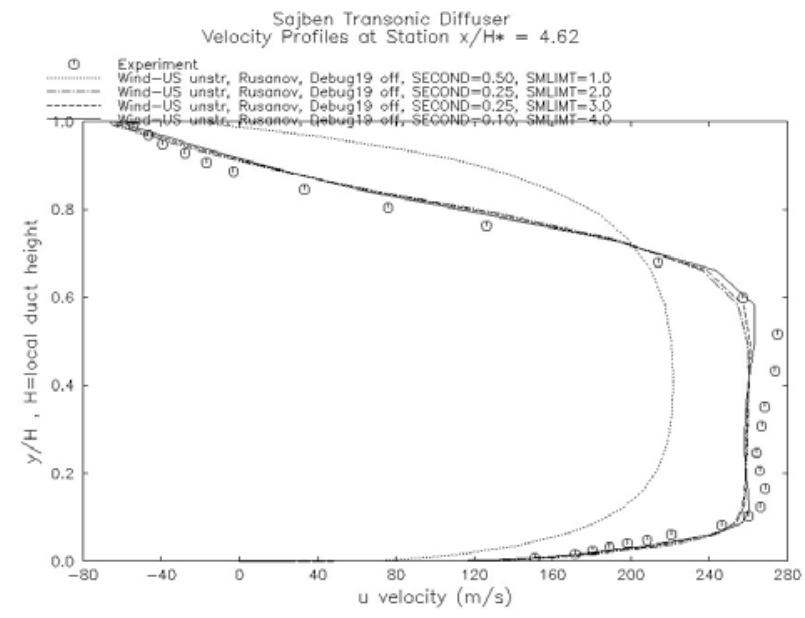

Figure 18.- Velocity profiles for various combinations of SECOND and SMLIMT.

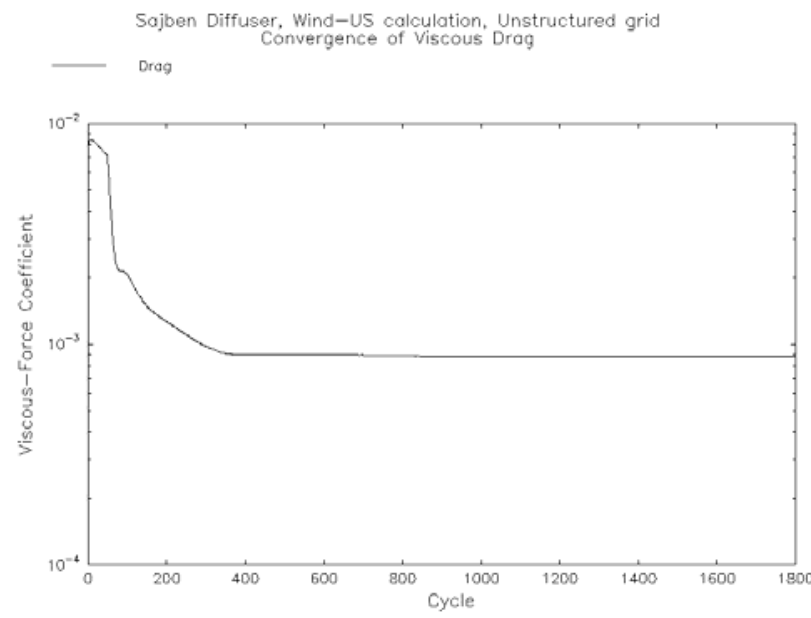

Figure 19.-Convergence of viscous drag using CONVERGE LOADS.

(Note: 5 iterations per cycle). 
residuals require at least 5000 iterations to attain any sort of levelness.

One imposes the CONVERGE LOADS strategy by commenting out the SMOOTHING keyword and adding CONVERGE LOADS, a DEBUG 24, and a LOADS section, like so:

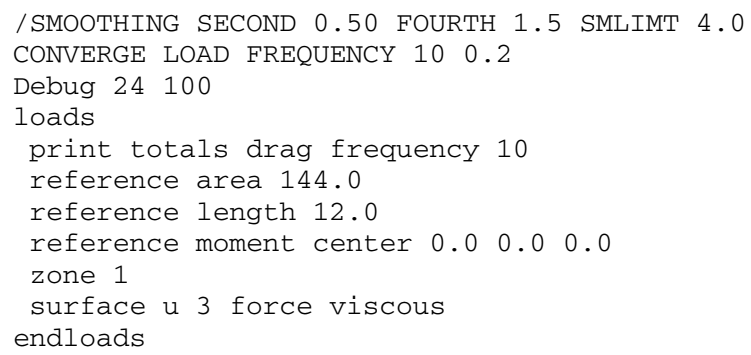

As the calculation proceeds, the upwind flux dissipation and slope limiting parameters are adjusted automatically if the relative changes in the forces and moments on the specified surfaces within the current zone, over the most recent 50 cycles, are all below the default value of 20 percent (specified as "0.2" above). Convergence is assumed, and the calculation ended, when the flux dissipation and slope limiting parameters have reached their limiting values in all zones, and the maximum relative change in the forces and moments, summed over all the zones, is less than the default value of 0.01 . (The convergence criterion of 0.01 is $1 /$ mode where mode is specified using DEBUG 24 mode with mode $=100$. A note of warning: the author of the current study found one case where too stringent a value of mode, in particular, a value of 1000 , precluded the calculation from halting because the unsteadiness in the loads was always larger than 0.001 of the loads themselves.)

At those times when Wind-US automatically

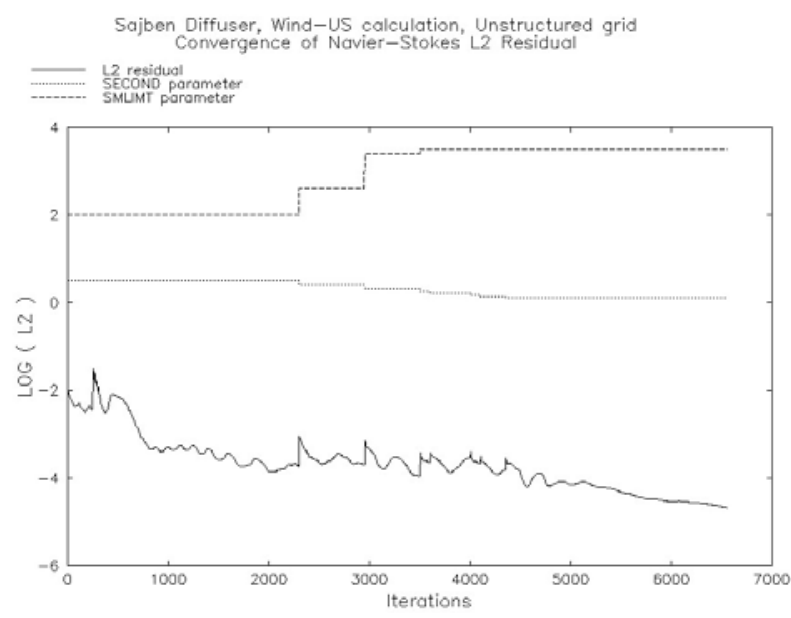

Rusanov versus Roe (Unstructured)

Figure 20.-Convergence of unstructured N-S L2 with automatic changes to SECOND and SMLIMT

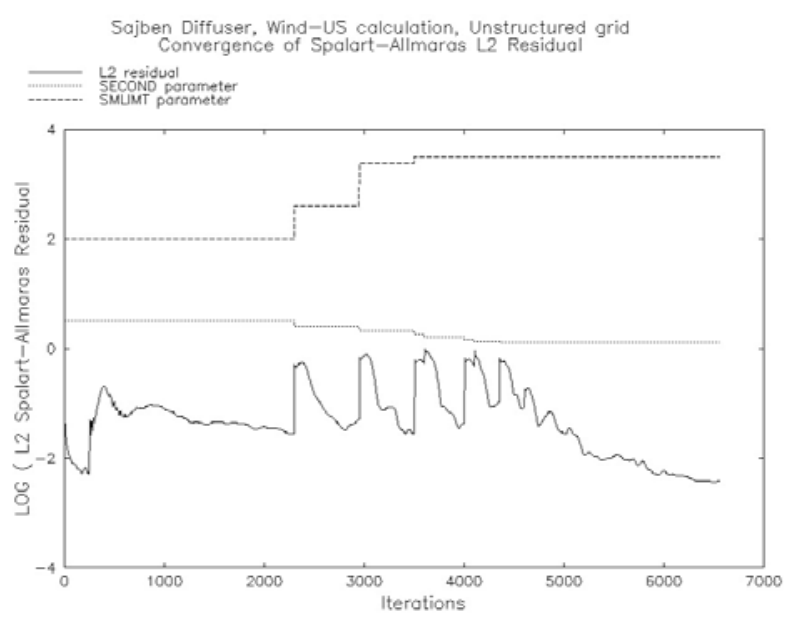

Figure 21.-Convergence of unstructured S-A L2 with automatic changes to SECOND and SMLIMT. adjusts SECOND or SMLIMT, it will print an output line to the LIS file like the following example:

*SMOOTH* $46014.000 \mathrm{E}-012.600 \mathrm{E}+00$

This example indicates that at Cycle 460, in Zone 1, SECOND was reduced to 0.4 and SMLIMT was raised to 2.6. The Rusanov scheme starts SECOND at 0.5 and changes it by actor of 0.8 until SECOND drops to a minimum of 0.1. SMLIMT starts at 1.0 and is raised by a factor of 1.3 until it reaches a maximum of 3.5. The Roe scheme does not use SECOND, but drives SMLIMT upward to 2.5.

An example of the L2 history with automatic adjustment of the upwind flux dissipation and slope limiter is shown in figure 20. The two stair-step curves show how Wind-US lowered the flux dissipation and raised the slope limiter over time. One can see how each adjustment caused the L2 to immediately jump up for a time. These jumps in L2 are more pronounced in the Spalart-Allmaras residuals, shown in figure 21 . 


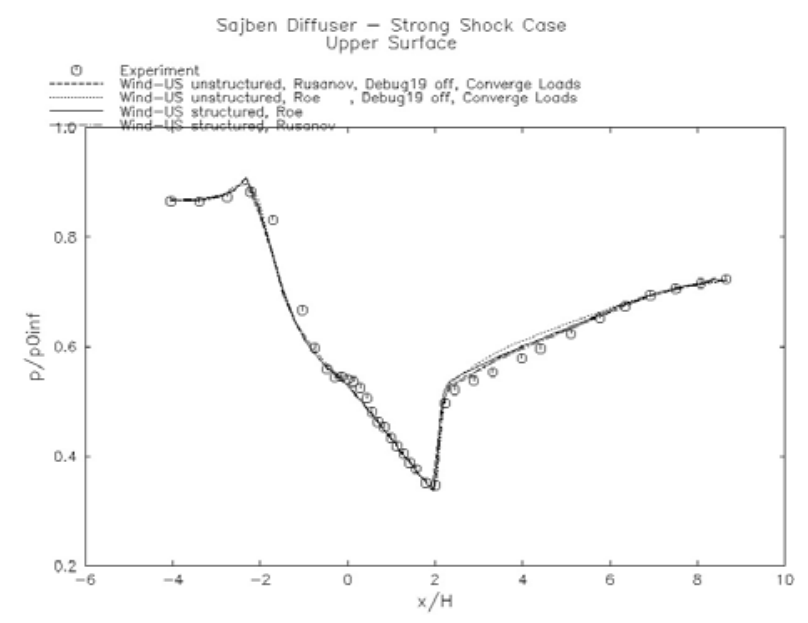

Figure 22a.-Upper wall static pressurescomparison of unstructured and structured, Rusanov and Roe.

\section{Rusanov versus Roe (Unstructured)}

With the values of SECOND and SMLIMT left to automatic adjustment by the CONVERGE LOADS strategy, the Rusanov unstructured calculation was compared to a Roe unstructured calculation. Figures 22a and 22b include a comparison of upper wall static pressures computed by Rusanov and Roe. The unstructured Rusanov scheme is closer than unstructured Roe to experiment near the shock and in the complex separated flow downstream of the shock. Figure 23 shows velocity profiles for Roe and Rusanov at station $\mathrm{x} / \mathrm{H}^{*}=4.62$. Both unstructured solvers appear to agree well with experiment, with Rusanov arguably marginally better.

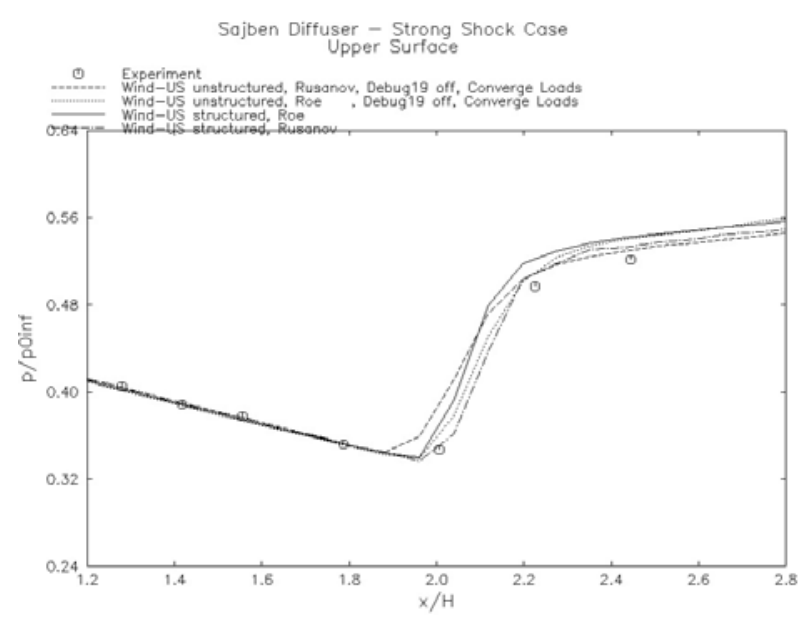

Figure 22b.-Close-up of figure 22a.

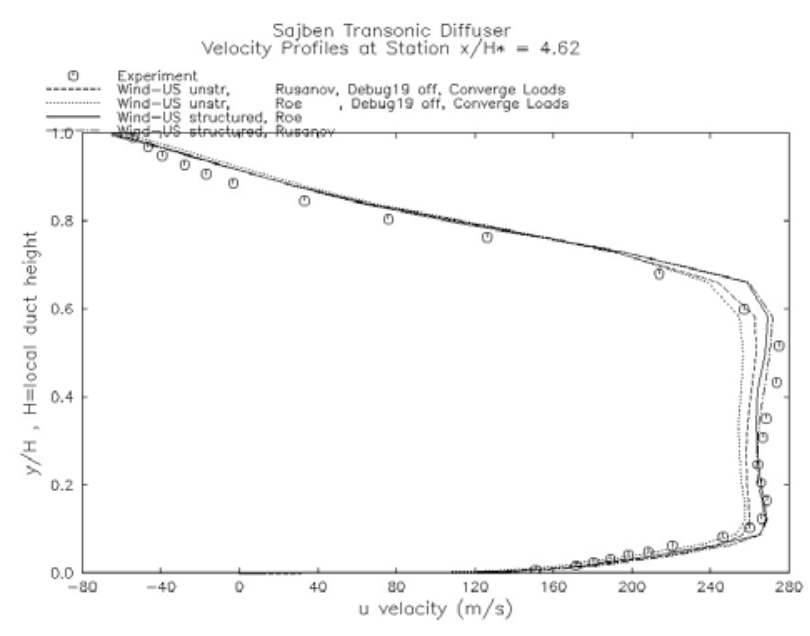

Figure 23.- Velocity profile-comparison of unstructured and structured, Rusanov and Roe.

\section{Structured versus Unstructured}

To run the structured Rusanov solver, one must include the following keywords in the ".dat" WindUS input file:

RHS RUSANOV SECOND PHYSICAL RUSANOV EPSS 0.1

The "0.1" is the upwind flux dissipation used in this study (but which defaults to 0.5). Note that the structured solver doesn't have the same TVD slope limiter as the unstructured. The default "Super-Bee" limiter was used here.

On a dedicated SGI Octane2, running on one $600 \mathrm{MHz}$ R14000 CPU, the structured solver computed 528 iterations per minute. The unstructured solver computed 283 iterations per minute. Therefore the structured solver iterated 1.86 times faster. However, for the structured solver, the residuals converged in 16,000 iterations (fig. 24) while the unstructured solver, using minimal smoothing, converged in about 7,000 iterations (figs. 5 and 6). Therefore both solvers converged the residuals in 30 minutes. As 
explained in the Computational Approach section, under subheading Input Parameters, the unstructured solver used a CFL number of 10. The structure solver only used 1.5 . For this 2-D problem, memory requirements were very similar: $29 \mathrm{MB}$ for unstructured, $33 \mathrm{MB}$ for structured. However, in general, 3-D unstructured grid requires significantly more memory than a comparable structured grid.

The previously discussed figures 22 and 23 compare unstructured Rusanov and Roe to structured Rusanov and Roe. All four methods produce similar wall pressures and velocity profiles.

For upper wall pressures, the structured/unstructured Roe schemes appear in

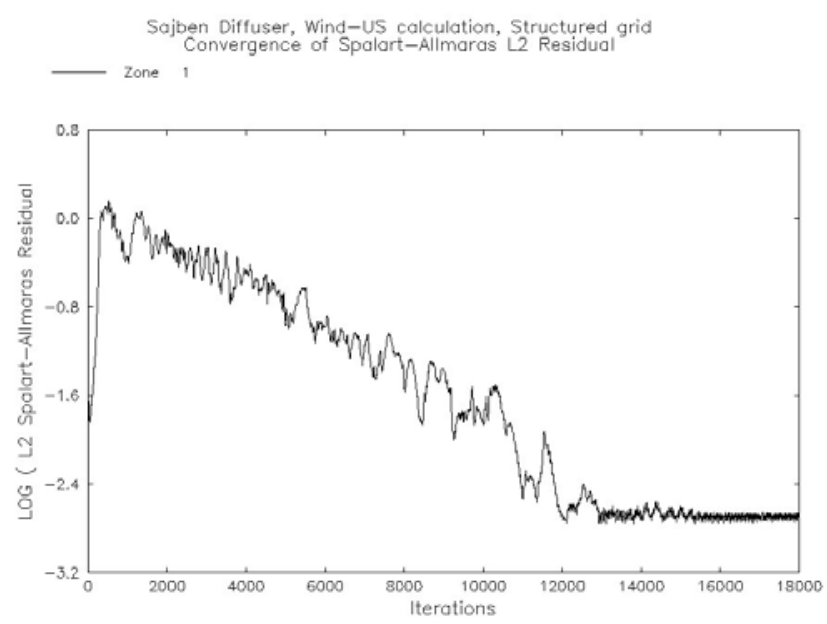
closer agreement to each other than the structured/unstructured Rusanov schemes. Unstructured Roe is noticeably worse than the others downstream of the shock.

\section{Conclusion}

For a transonic diffuser with a normal shock and shock-induced flow separation, the unstructured Wind-US solver produced good agreement with experimental static pressures and velocity profiles, as did the structured solver previously to this study.

For the unstructured solver, avoidance of excessive smoothing was essential for accurate solution and would be critical for making fair comparisons of unstructured Wind-US with other solvers that use different kinds of dissipation or different turbulence models (similar to what was done in ref. 10). Regardless of the value of SECOND, setting SMLIMT=1.0 always gave a bad solution, especially if SECOND was greater than 0.25 . Setting SMLIMT $=1.0$ can be used to stabilize transient solutions, but SMLIMT must be raised to 2.0 or more for final convergence. Solutions using SMLIMT=2.0 or above show little variation, but higher values do produce more accurate solutions and should be used unless instabilities preclude such. SECOND can be set to 0.5 for stability, but should be 0.25 or less for better accuracy.

Use of the CONVERGE LOADS convergence strategy provided a good, automatic smoothing strategy and shorter run times. The modified Rusanov scheme is preferred over Roe for unstructured Wind-US calculations. The constant enthalpy scheme (DEBUG 19 input option) should probably be avoided except for hypersonic flows.

\section{References}

1. Nelson, C.C. and Power, G.D., "CHSSI Project CFD-7: The NPARC Alliance Flow Simulation System," AIAA-2001-0594, January 2001.

2. NPARC Alliance, "Wind-US User's Guide," October 2003.

3. Mani, M., Cary, A., Ramakrishnan, S.V., "A Structured and Hybrid-unstructured Grid Euler and NavierStokes Solver for General Geometry," AIAA-2003-0524, January 2004.

4. Liu, Z., Ramakrishnan, S.V., Biharai, B., Olling, C.R., Dominik, D.F., "Aeroheating Prediction Using the Hybrid Flow Solver, ICAT," AIAA-2002-2936, June 2002.

5. Mohler, S.R., "Wind-US Flow Calculations for the M2129 S-Duct Using Structured and Unstructured Grids," NASA/CR-2003-212736, AIAA-2004-0525, January 2004.

6. Bogar, T.J., Sajben, M., and Kroutil, J.C., "Characteristic Frequencies of Transonic Diffuser Flow Oscillations," AIAA Journal, vol. 21, no. 9, pp. 1232-1240, September 1983. 
7. Bogar, T.J., "Structure of Self-Excited Oscillations in Transonic Diffuser Flows," AIAA Journal, vol. 24, no. 1, pp. 54-61, Jan., 1986.

8. Hsieh, T., Wardlaw A.B. Jr., Bogar, T.J., and Coakley, T.J. (1987) "Numerical Investigation of Unsteady Inlet Flowfields,” AIAA Journal, vol. 25, no. 1, pp. 75-81, January 1987.

9. Hsieh, T., Bogar, T.J., and Coakley, T.J., "Numerical Simulation and Comparison with Experiment for Self-Excited Oscillations in a Diffuser Flow,” AIAA Journal, vol. 25, no. 7, pp. 936-943, July 1987.

10. Georgiadis, N.J., Drummond, J.E., and Leonard, B.P., "Evaluation of Turbulence Models in the PARC Code for Transonic Diffuser Flows," NASA TM-106391, Jan. 1994.

11. Anderson, J.D., "Computational Fluid Dynamics: The Basic Applications," McGraw-Hill, New York, 1995, p. 509. 
Public reporting burden for this collection of information is estimated to average 1 hour per response, including the time for reviewing instructions, searching existing data sources, gathering and maintaining the data needed, and completing and reviewing the collection of information. Send comments regarding this burden estimate or any other aspect of this collection of information, including suggestions for reducing this burden, to Washington Headquarters Services, Directorate for Information Operations and Reports, 1215 Jefferson Davis Highway, Suite 1204, Arlington, VA 22202-4302, and to the Office of Management and Budget, Paperwork Reduction Project (0704-0188), Washington, DC 20503. \begin{tabular}{|l|l|l}
\hline 1. AGENCY USE ONLY (Leave blank) & $\begin{array}{c}\text { 2. REPORT DATE } \\
\text { January } 2005\end{array}$ & $\begin{array}{c}\text { 3. REPORT TYPE AND DATES COVERED } \\
\text { Final Contractor Report }\end{array}$
\end{tabular}

4. TITLE AND SUBTITLE 5. FUNDING NUMBERS

Wind-US Unstructured Flow Solutions for a Transonic Diffuser

6. $\operatorname{AUTHOR(S)}$

WBS-22-066-50-01

Stanley R. Mohler, Jr. NAS3-00145

7. PERFORMING ORGANIZATION NAME(S) AND ADDRESS(ES)

8. PERFORMING ORGANIZATION REPORT NUMBER

QSS Group, Inc.

21000 Brookpark Road

E-14939

Cleveland, Ohio 44135

9. SPONSORING/MONITORING AGENCY NAME(S) AND ADDRESS(ES)

National Aeronautics and Space Administration

Washington, DC 20546-0001

10. SPONSORING/MONITORING AGENCY REPORT NUMBER

NASA CR-2005-213417

AIAA-2005-1004

\section{SUPPLEMENTARY NOTES}

Prepared for the 43rd Aerospace Sciences Meeting and Exhibit sponsored by the American Institute of Aeronautics and Astronautics, Reno, Nevada, January 10-13, 2005. Project Manager, David A. Sagerser, Aeropropulsion Research Program Office, NASA Glenn Research Center, organization code PRX, 216-433-2172.

12a. DISTRIBUTION/AVAILABILITY STATEMENT 12b. DISTRIBUTION CODE

Unclassified - Unlimited

Subject Category: 34

Distribution: Nonstandard

Available electronically at http://gltrs.grc.nasa.gov

This publication is available from the NASA Center for AeroSpace Information, 301-621-0390.

13. ABSTRACT (Maximum 200 words)

The Wind-US Computational Fluid Dynamics flow solver computed flow solutions for a transonic diffusing duct. The calculations used an unstructured (hexahedral) grid. The Spalart-Allmaras turbulence model was used. Static pressures along the upper and lower wall agreed well with experiment, as did velocity profiles. The effect of the smoothing input parameters on convergence and solution accuracy was investigated. The meaning and proper use of these parameters are discussed for the benefit of Wind-US users. Finally, the unstructured solver is compared to the structured solver in terms of run times and solution accuracy.

14. SUBJECT TERMS

Computational fluid dynamics; Unstructured grids; Inlet flow; Transonic flow 15. NUMBER OF PAGES 19

\begin{tabular}{|c|c|c|}
\hline $\begin{array}{c}\text { 17. SECURITY CLASSIFICATION } \\
\text { OF REPORT } \\
\text { Unclassified }\end{array}$ & $\begin{array}{c}\text { 18. SECURITY CLASSIFICATION } \\
\text { OF THIS PAGE } \\
\text { Unclassified }\end{array}$ & $\begin{array}{c}\text { 19. SECURITY CLASSIFICATION } \\
\text { OF ABSTRACT } \\
\text { Unclassified }\end{array}$ \\
\hline
\end{tabular}

NSN 7540-01-280-5500 

